07

\title{
Особенности намагничивания магнитных коллоидных наносистем на парафиновой основе
}

\author{
(С Ю.И. Диканский, А.Г. Испирян, С.А. Куникин, А.В. Радионов \\ Северо-Кавказский федеральный университет, \\ 353029 Ставрополь, Россия \\ I e-mail: skunikin@yandex.ru
}

(Поступило в Редакцию 28 июня 2016 г. В окончательной редакции 25 мая 2017 г.)

Исследованы причины максимума зависимости магнитной восприимчивости магнитных коллоидов от температуры на примере магнитных коллоидных систем на парафиновой основе. Проведен анализ особенностей полученных зависимостей магнитной восприимчивости от температуры в широком температурном интервале при твердом и жидком состояниях коллоидов. Сделан вывод, что один из обнаруженных максимумов, наблюдающийся при температуре плавления парафина, связан с блокировкой броуновских степеней свободы части наиболее крупных частиц магнетита, магнитный момент которых жестко связан с твердой матрицей. Наличие основного второго максимума, соответствующего твердому состоянию образца, объяснено переходом большей части более мелких частиц при понижении температуры из суперпарамагнитного состояния в магнитожесткое. Указано, что пологость этого максимума связана со значительной полидисперсностью ансамбля магнитных наночастиц.

DOI: 10.21883/JTF.2018.01.45482.1945

\section{Введение}

Магнитные свойства магнитных коллоидных наносистем - магнитных жидкостей ранее рассматривались во многих работах, обзор первых из которых можно найти в ряде монографий (например, в [1]). Развитие исследований в этом направлении осуществлялось при рассмотрении особенностей релаксации магнитного момента однодоменных частиц, учета их взаимодействия [2-6] и связанных с ним структурными изменениями системы [7]. Одним из параметров, исследование которого позволяет провести анализ проявления этих процессов, является магнитная восприимчивость. Поэтому исследование ее функциональных зависимостей неоднократно предпринималось многими авторами [2-9]. Одним из интересных результатов в этой области является экспериментально обнаруженный максимум температурной зависимости восприимчивости, о котором, по-видимому, впервые сообщалось в работах [2,3] и впоследствии неоднократно исследовался в ряде работ $[4-6,10]$. Его наличие в [2] было объяснено потерей ориентационных степеней свободы магнитожестких однодоменных частиц при затвердевании дисперсионной среды. Аналогичное объяснение природы указанного максимума предлагалось в работах [4,5], вместе с тем в работе [6] он был связан с магнитным фазовым переходом системы в так называемое состояние „дипольного стекла“. Повидимому, отсутствие исчерпывающей ясности в этой проблеме способствует поддержанию к ней интереса. Об этом может свидетельствовать объяснение в последующих работах, например [9-11], причины экстремального характера зависимости магнитной восприимчивости посредством магнитного фазового перехода, о котором упоминалось выше. Следует отметить, что в большин- стве работ, посвященных этому вопросу, исследовались магнитные жидкости на основе керосина с дисперсными частицами магнетита, переход которых в твердое состояние происходит при температурах 200-240 К. Между тем известно, что в этой области температур возможно существенное изменение константы магнитной анизотропии магнетита, величина которой определяет переход системы в суперпарамагнитное состояние. Кроме того, в интервале температур 100-200 К, температурная зависимость спонтанной намагниченности магнетита имеет экстремальный характер. Это создает определенные трудности при рассмотрении причин наблюдаемого в этой области температур максимума температурной зависимости восприимчивости магнитной жидкости. В связи с этим в настоящей работе подобные исследования проведены для магнитных коллоидных наносистем, переход дисперсионной среды которых из жидкого состояния в твердое может осуществляться при комнатных температурах. Кроме того, были проведены также исследования особенностей их намагничивания, остаточной намагниченности и зависимости ее от времени, позволяющие получить дополнительную информацию о механизмах релаксации магнитных моментов наночастиц.

\section{Методика измерений и образцы для исследования}

Исследование динамической магнитной восприимчивости в широком температурном интервале (от 77 до $380 \mathrm{~K}$ ) проводилось мостовым методом. Измерение намагниченности осуществлялось с помощью вибрационного магнетометра, кроме того, для исследования 

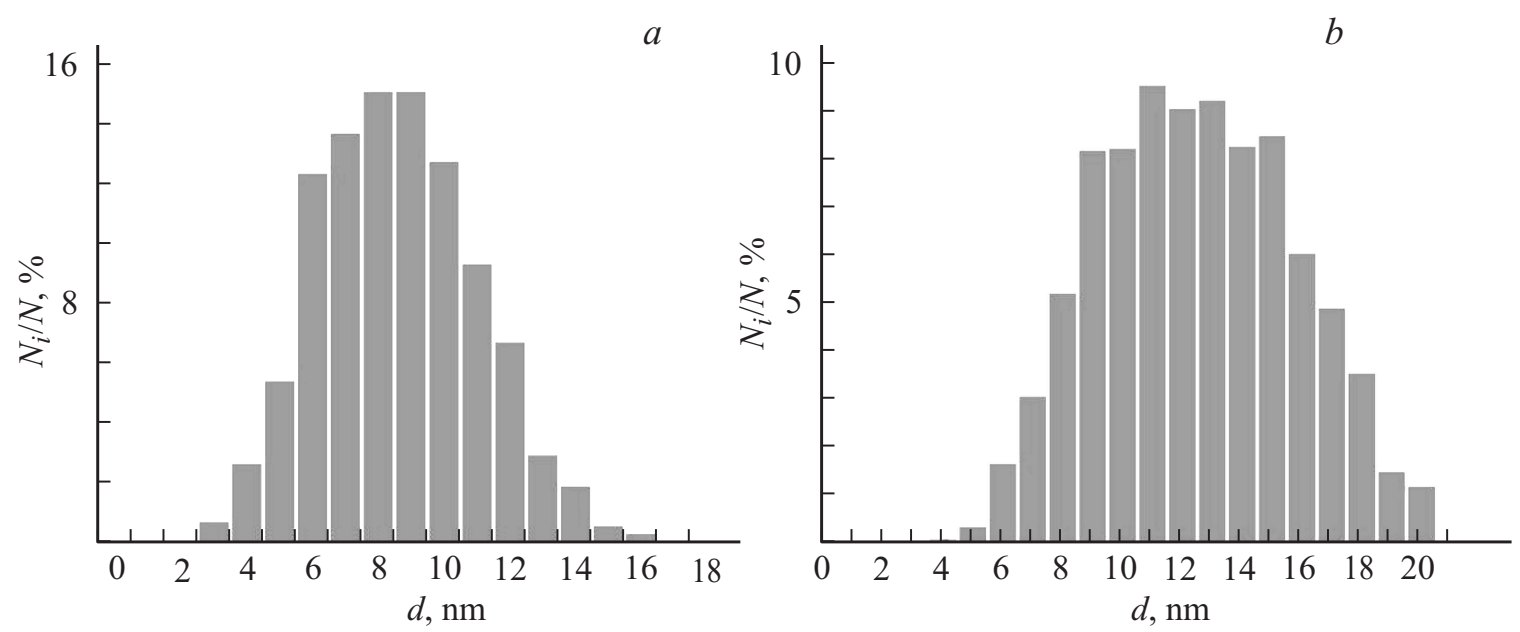

Рис. 1. Гистограмма распределения дисперсных частиц по размерам, определенная путем анализа данных просвечивающей электронной микроскопии: $a-$ образец № $1 ; b-$ образец № 2.

остаточной намагниченности и ее релаксации использовался баллистический метод. Подробное описание всех использованных методов приведено в [11].

В качестве объектов исследования были использованы два образца магнитной жидкости с магнетитовыми частицами на парафиновой основе, намагниченность насыщения которых составляла 80.2 и $28.0 \mathrm{kA} / \mathrm{m}$. Образец № 1 получен по стандартной методике путем химического осаждения магнетита из солей железа, в качестве стабилизатора использовалась олеиновая кислота. Образец № 2 был получен путем смешивания расплава парафина с пастой из частиц магнетита, полученной выпариванием носителя из магнитной жидкости на основе керосина с олеиновой кислотой в качестве стабилизатора с высокой (> 25\%) концентрацией дисперсных частиц.

Гранулометрический состав образцов был определен по результатам просвечивающей электронной микроскопии, выполненной компанией „Системы микроскопии и анализа" (Сколково, Россия) на микроскопе FEI Tecnai G2 F20 S-Twin TMP. Для получения образца для измерений магнитная жидкость на парафиновой основе осаждалась в градиентном магнитном поле горячим толуолом. При этом магнитная фаза отделялась от носителя - парафина. Распределение дисперсных частиц по размерам представлено на рис. 1. Для магнетитовых частиц известно, что если их размер не превышает величину в $50 \mathrm{~nm}$, то они находятся в однодоменном состоянии. Таким образом, оба образца представляют собой ансамбли однодоменных магнетитовых частиц.

\section{Результаты исследований}

На рис. 2, а приведена температурная зависимость магнитной восприимчивости образца № 1 на основе парафина (кривая 2). Как видно из рисунка, первоначально при увеличении температуры наблюдается рост магнитной восприимчивости, который, однако, замедляется с выходом на плато при температурах, близких к 273 K, на котором в интервале температур 273-323 К прослеживается слабо выраженный пологий максимум. При температуре, соответствующей переходу образца из твердого состояния в жидкое $(323 \mathrm{~K})$, наблюдается
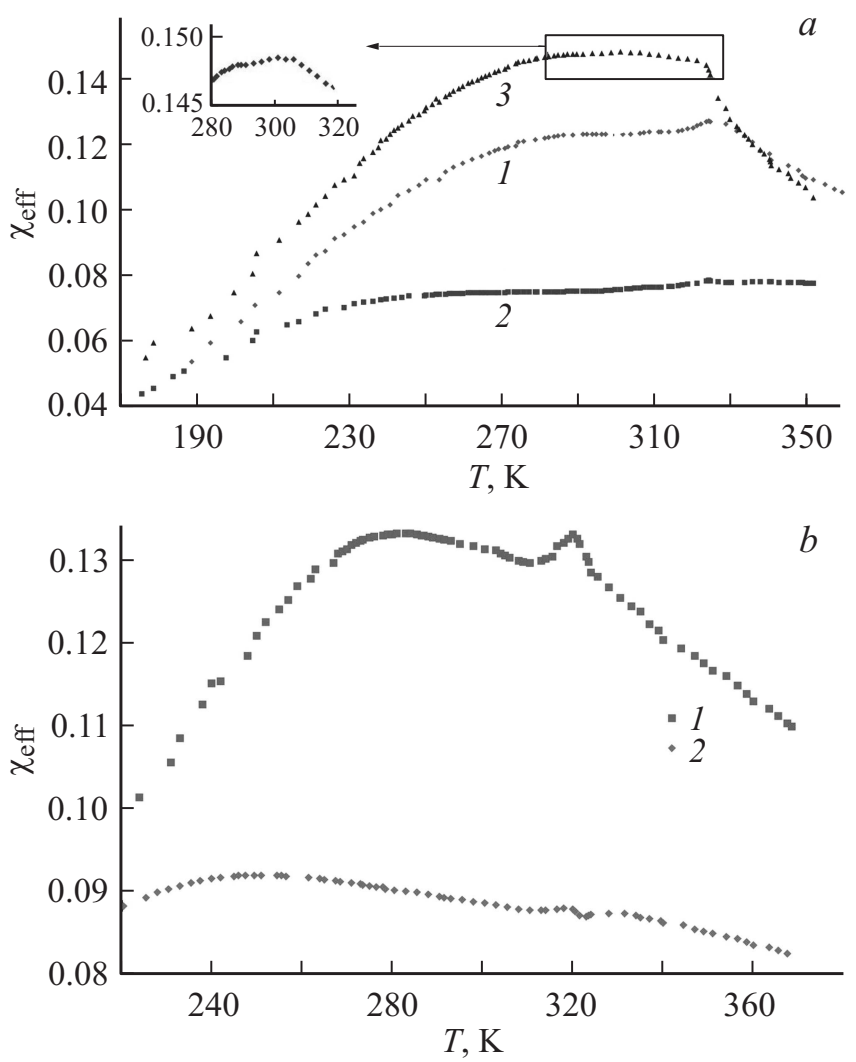

Рис. 2. Температурная зависимость магнитной восприимчивости образца № $1(a)$ и № $2(b)$. 1 - образец охлажден в магнитном поле, 2 - магнитное поле отсутствует, 3 постоянное подмагничивающее поле $9.7 \mathrm{kA} / \mathrm{m}$. 
небольшой острый максимум, а затем резкое уменьшение магнитной восприимчивости. Такой же характер, но с более выраженными максимумами имеет и кривая температурной зависимости магнитной восприимчивости образца № 2 (рис. 2, $b$, кривая 1 ). Дополнительное воздействие постоянного магнитного поля приводит к уменьшению магнитной восприимчивости исследованных образцов, но не изменяет характер их температурной зависимости (кривая 3, рис. 2, $a$ и кривая 2, рис. 2, b). Была также исследована магнитная восприимчивость одного из образцов (№ 1) после отверждения его расплава в магнитном поле. Для этого кювету с расплавленным образцом помещали в соленоид, создававшим магнитное поле напряженностью $24.8 \mathrm{kA} / \mathrm{m}$, и выдерживали в нем при комнатной температуре до перехода в твердое состояние. После этого кювета с образцом удалялась из поля, охлаждалась до температуры $77 \mathrm{~K}$ и возвращалась в измерительную систему, с помощью которой проводились исследования температурной зависимости магнитной восприимчивости. Оказалось, что в этом случае восприимчивость такой магнитной жидкости значительно увеличивается $(\approx 20 \%)$ при сохранении характера ее температурной зависимости, при этом температура, соответствующая максимальному значению восприимчивости остается несколько ниже температуры плавления (рис. 2, a, кривая 3). Очевидно, после отверждения

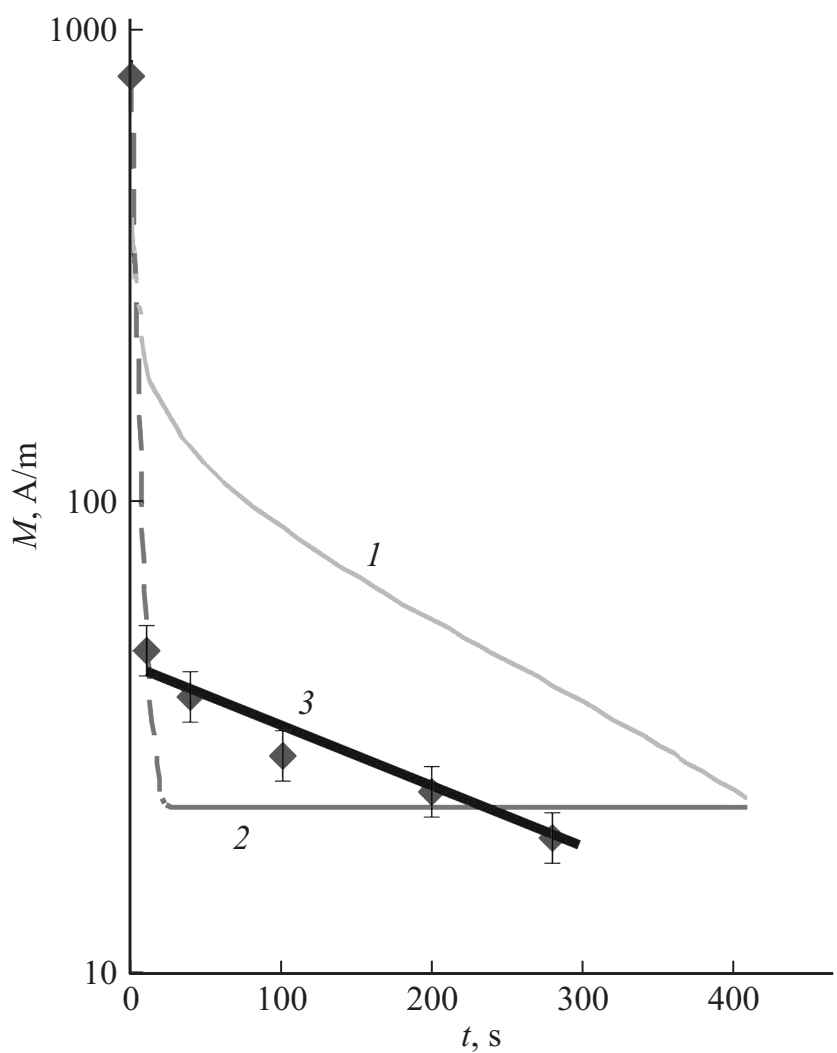

Рис. 3. Релаксация остаточной намагниченности образца № 1 при комнатной температуре: 1 - степенная функция, $2-$ экспоненциальная, 3 - экспоненциальная без учета первой точки экспериментально полученная зависимость.

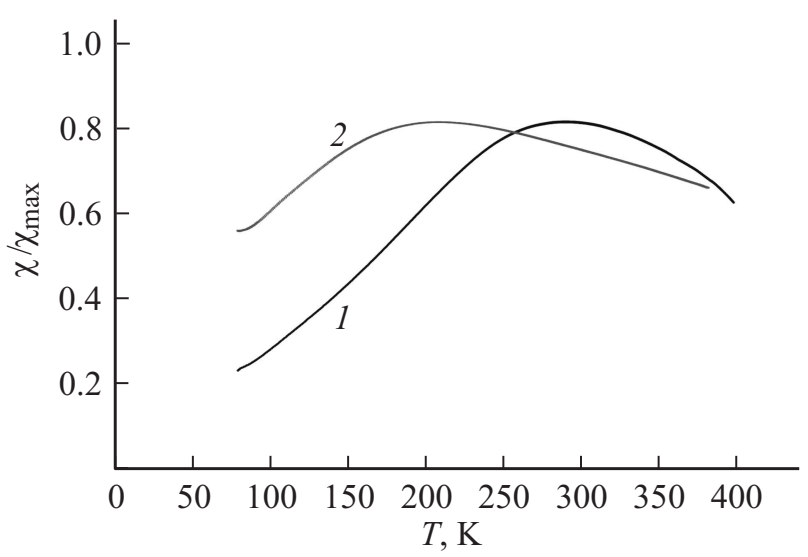

Рис. 4. Температурная зависимость магнитной восприимчивости пасты из магнетитовых частиц: 1 - магнитное поле отсутствует, 2 - постоянное подмагничивающее поле $9.7 \mathrm{kA} / \mathrm{m}$.

такой магнитной жидкости в магнитном поле в ней сохраняется структурная анизотропия после выключения поля, которая обусловливает анизотропию магнитной восприимчивости образца.

Кроме того, были проведены исследования возможности возникновения остаточной намагниченности в образце, отвердевшем в магнитном поле. Оказалось, что в таких образцах действительно обнаруживается остаточная намагниченность, величина которой релаксирует к постоянной величине в течение некоторого времени. На рис. 3 (точки) представлена зависимость остаточной намагниченности от времени образца, охлажденного до температуры ниже точки плавления $(293 \mathrm{~K})$ в магнитном поле, напряженностью $28.7 \mathrm{kA} / \mathrm{m}$, полученная с помощью баллистического метода.

Исследование пасты из частиц магнетита, диспергированием которой в расплавленном парафине был получен описанный выше образец, показало, что температурная зависимость ее магнитной восприимчивости также претерпевает максимум в окрестности температуры $273 \mathrm{~K}$ (рис. 4, кривая 1), который существенно смещается в область более низких температур при воздействии постоянного магнитного поля (кривая 2). Было также установлено, что увеличение частоты измерительного поля приводит к смещению максимума в область более высоких температур. Отметим, что подобный характер температурной зависимости восприимчивости был обнаружен нами ранее при исследовании сухого порошка из частиц магнетита, полученного выпариванием магнитной жидкости на основе керосина [11].

\section{Обсуждение результатов исследования}

Анализ полученных температурных зависимостей магнитной восприимчивости исследованного образца позволяет утверждать, что ее особенности действительно могут быть связаны с затвердеванием основы 
и блокировкой броуновских степеней свободы магнитожестких частиц. Об этом может свидетельствовать острый экстремум на температурной зависимости магнитной восприимчивости, наблюдающийся при температуре, соответствующей плавлению дисперсионной среды (парафина). Вместе с тем следует отметить наличие еще одного более пологого максимума при температуpax ниже плавления парафина, который смещается при дополнительном воздействии постоянного магнитного поля в область более низких температур. Особенно четко это прослеживается для образца № 2 (рис. 2,b). Кроме того, температурная зависимость пасты из частиц магнетита, послужившей основой для приготовления магнитной жидкости на основе парафина, также претерпевает максимум, который не может быть связан с затвердеванием дисперсионной среды вследствие ее отсутствия. Можно предположить, что острый максимум температурной зависимости магнитной восприимчивости, наблюдающийся при температуре плавления парафина, действительно связан с блокировкой броуновских степеней свободы части наиболее крупных частиц магнетита, магнитный момент которых жестко связан с твердой матрицей. Наличие основного пологого максимума, соответствующего твердому состоянию образца, может быть объяснено переходом большей части более мелких частиц при повышении температуры в суперпарамагнитное состояние, релаксация магнитного момента частиц при котором определяется неелевским механизмом. При этом „размытость“ максимума связана с распределением частиц по размерам и, как следствие, с распределением времен релаксации в некотором интервале времени. Действительно, максимум магнитной восприимчивости магнитной коллоидной системы может быть связан с блокировкой броуновских степеней свободы только в том случае, если частицы при понижении температуры перестали быть суперпарамагнитными еще при температуре, соответствующей жидкому состоянию образца. Наличие подобного максимума температурной зависимости восприимчивости уже отвердевшей магнитной жидкости может быть объяснено переходом частиц из суперпарамагнитного состояния в магнитожесткое. Обнаруженное смещение температуры максимума магнитной восприимчивости магнитного коллоида на основе парафина от дополнительного воздействия магнитного поля, а также частоты измерительного магнитного поля может свидетельствовать в подтверждение этого. Отметим, что результаты проведенных исследований позволяют сделать вывод о необходимости учета возможности изменения механизмов релаксации магнитного момента однодоменных частиц магнитных коллоидов при изменении температуры, концентрации частиц, воздействия магнитного поля и изменении частоты измерительного поля. В частности, вызывает сомнение возможность интерпретации результатов частотных исследований комплексной магнитной восприимчивости на основе теории Дебая [12], так как один и тот же ансамбль однодоменных частиц может быть как суперпа- рамагнитным, так и ферромагнитным в зависимости от времени действия измерительного поля. Действительно, для наблюдения перехода системы в суперпарамагнитное состояние необходимо, чтобы времена релаксации $\tau$, и измерения $\tau_{\exp }$ были близкими по величине [13]. Время неелевской релаксации определяется выражением

$$
\tau=\tau_{0} \exp \left(\frac{\Delta E}{k T}\right),
$$

где $\tau_{0} \approx 10^{-9}-10^{-10} \mathrm{~s}, \Delta E-$ энергетический барьер, который необходимо преодолеть для поворота момента частицы по полю при изменении его направления. Вращение магнитных моментов однодоменных частиц является термически активированным во время проведения эксперимента, если для энергетического барьера выполняется условие $\Delta E \leqslant \ln \frac{\tau_{\text {exp }}}{\tau_{0}} k T$. Таким образом, переход ансамбля частиц в суперпарамагнитное состояние определяется кроме прочих известных параметров (диаметра частиц, величины константы магнитокристаллической анизотропии, температуры) также и временем измерения $\tau_{\exp }$ (в случае переменного поля - периодом его изменения). Следует отметить, что ситуация для реальных образцов магнитных коллоидных систем усложняется также вследствие полидисперсности системы, в результате чего при повышении частоты переход к стабильности у разных частиц происходит при разной ее величине.

Воздействие магнитного поля на жидкий образец приводит к его намагничиванию за счет ориентации магнитных моментов частиц, при этом возможен как поворот момента относительно матрицы, так и поворот самой частицы в случае ее стабильности. После перехода помещенного в магнитное поле жидкого образца в твердое состояние при понижении температуры происходит блокировка броуновских степеней свободы частиц. Размагничивание такого образца возможно только за счет статистического изменения направлений векторов магнитного момента внутри частиц под действием тепловых флуктуаций. В этом случае зависимость намагниченности образца от времени после выключения поля должна иметь вид, характерный для ансамбля суперпарамагнитных частиц, т. е. $M_{r}=M_{0} \exp \left(-\frac{t}{\tau}\right)$. При этом наличие взаимодействия частиц не должно изменить экспоненциальный характер этой зависимости, так как его учет, как показано в [14], можно осуществить путем добавления в формулу для расчета энергетического барьера дополнительного слагаемого, характеризующего возникающий барьер за счет взаимодействия частиц. С другой стороны, в случае предположения, сделанного в ряде работ $[6,10]$, о возможности в магнитных жидкостях состояния так называемого „дипольного стекла“, зависимость остаточной намагниченности должна описываться степенной функцией типа

$$
M_{r}=M_{0}\left(\frac{t}{\tau}\right)^{-\alpha}
$$


Анализ полученной зависимости $M_{r}(t)$ показал ее отличие как от экспоненциальной, так и степенной функций (кривые 1 и 2 на рис. 4 соответственно).

Следует, однако, заметить, что вследствие полидисперсности системы, которая приводит к распределению времен релаксации наночастиц в некотором интервале, зависимость должна быть выражена соотношением [15]:

$$
M_{r}=M_{0} \int_{0}^{\infty} \frac{f(\tau)}{\tau} e^{\frac{t}{\tau}} d \tau,
$$

где $f(\tau)$ - функция распределения по временам релаксации.

В результате этого уменьшение остаточной намагниченности ансамбля однодоменных частиц от времени, связанное с тепловыми флуктуациями, может не описываться простой экспоненциальной функцией во всем исследуемом интервале времен. Действительно, в первый момент времени после выключения поля происходит разориентация моментов достаточно мелких частиц, в результате чего происходит скачкообразное уменьшение намагниченности системы. В последующем в изменение намагниченности начинают вносить вклад более крупные частицы, для которых времена релаксации моментов соизмеримы со временем наблюдения. Очевидно, именно эту ситуацию отражает полученный экспериментально отрезок приведенной выше на рис. 3 зависимости $M_{r}(t)$, начало которого соответствует второй экспериментальной точке (первая точка соответствует намагниченности образца в приложенном поле, напряженностью $H=27 \mathrm{kA} / \mathrm{m})$. Таким образом, можно предположить, что наличие остаточной намагниченности исследуемой магнитной жидкости на основе парафина связано с магнитным последействием в мелких частицах, обусловливающих процессы магнитной вязкости.

Результаты исследования температурной зависимости магнитной восприимчивости высококонцентрированной пасты магнитной жидкости, в которой исключены броуновские степени свободы частиц во всем исследуемом температурном интервале, позволяют также связать наблюдаемые максимумы их температурной зависимости магнитной восприимчивости с переходом в суперпарамагнитное состояние. Подтверждением этого могут служить факты смещения максимума в область более низких температур при дополнительном приложении постоянного магнитного поля и, напротив, в область более высоких температур при увеличении частоты измерительного поля.

В заключение отметим, что обнаруженная анизотропия магнитной восприимчивости отвержденных в магнитном поле образцов, по-видимому, обусловлена структурной анизотропией, сформировавшейся под воздействием внешнего постоянного поля, благодаря наличию фракции наиболее крупных частиц. Структурная анизотропия также может вносить определенный вклад и в остаточную намагниченность такой системы. Это связано с тем, что при объединении частиц в структурные образования происходит уменьшение расстояния между отдельными частицами, а следовательно, увеличение энергии их взаимодействия. В свою очередь, как уже было указано выше, это приводит к увеличению энергетического барьера, в результате чего частица может приобрести стабильность, т. е. стать магнитожесткой и повысить остаточную намагниченность отвердевшей исследуемой среды.

Работа выполнена при поддержке грантов РФФИ (проект № 16-03-00054) и Министерства образования Российской Федерации.

\section{Список литературы}

[1] Блум Э.Я., Майоров М.М., Цеберс А.О. Магнитные жидкости. Рига: Зинатне, 1989. 386 с.

[2] Диканский Ю.И. // Магнит. гидродинамика. 1982. № 3. C. 33.

[3] O'Grady K., Popplewell J., Charles S.W. // J. Magn. Magn. Mater. 1983. Vol. 39. N 56.

[4] Пшеничников А.Ф., Лебедев А.В., Морозов К.И. // Магнит. гидродинамика. 1987. № 1. С. 37-43.

[5] Пшеничников А.Ф., Лебедев А.В. // Коллоид. журн. 2005. T. 67. № 2. C. 218-230.

[6] Минаков А.А., Мягков А.В., Зайцев И.А., Веселаго В.Г. // Изв. АН СССР. Сер. физ. 1987. Т. 51. С. 1062.

[7] Гладких Д.В., Диканский Ю.И., Балабанов К.А., Радионов А.В // ЖТФ. 2005. Т. 75. Вып. 1. С. 139.

[8] Fannin P.C., Scaife B.K.P., Charles S.W. // J. Phys. D. Appl. Phys. 1988. Vol. 21. P. 1035.

[9] Zhang J., Boyd C., Luo W. // Phys. Rev. Lett. 1996. Vol. 77. P. 390 .

[10] Morales M.B., Phan M.H., Pal S., Frey N.A., Srikanth H. // JAP. 2009. Vol. 105. 07B511.

[11] Куникин С.А., Диканский Ю.И. // ЖТФ. 2010. Т. 80. Вып. 1. C. 112.

[12] Fannin P.C., Mac Oireachtaigh C., Bertrand E., CohenTannoudji L., Bibette J. // J. Magn. Magn. Mater. 2006. Vol. 300. P. 210-212.

[13] Zorn R. // J. Chem. Phys. 2002. Vol. 116. P. 3204.

[14] Dormann J.L., Bessais L., Fiorani D. // J. Phys. C: Sol. Stat. Phys. 1988. Vol. 21. P. 2015.

[15] Ивановский В.И., Черникова Л.А Физика магнитных явлений. Москва: МГУ, 1981. 288 с. 